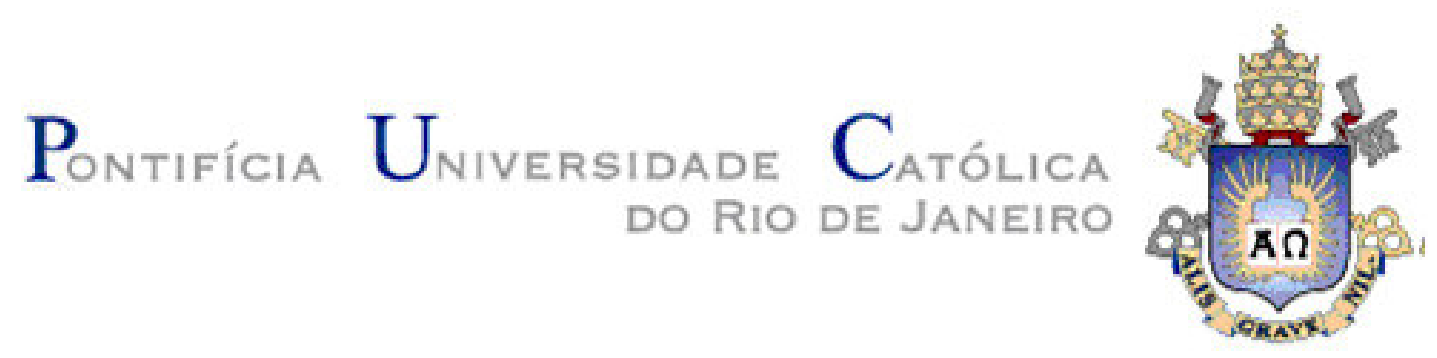

André Luiz de Souza Portugal

\begin{abstract}
Aplicação da teoria das Opções Reais na avaliação de uma usina hidrelétrica
\end{abstract}

Dissertação de Mestrado

Dissertação apresentada como requisito parcial para obtenção do grau de Mestre pelo Programa de Pós-graduação em Administração do Departamento de Administração da PUC-Rio.

Orientador: Prof. Luiz Eduardo Teixeira Brandão

Rio de Janeiro

Outubro de 2007 


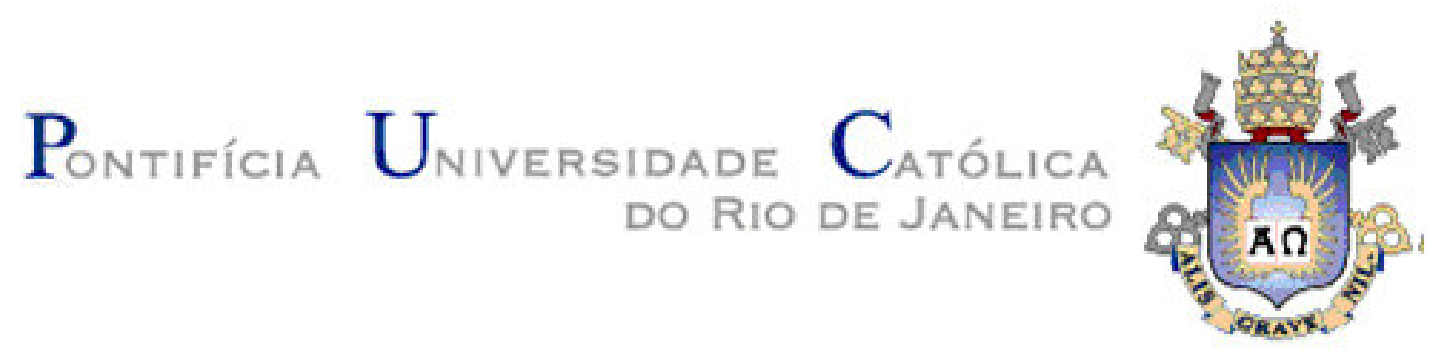

André Luiz de Souza Portugal

\section{Aplicação da teoria das Opções Reais na avaliação de uma usina hidrelétrica}

Dissertação apresentada como requisito parcial para obtenção do grau de Mestre pelo Programa de Pós-graduação em Administração do Departamento de Administração da PUC-Rio. Aprovada pela Comissão Examinadora abaixo assinada.

Prof. Luiz Eduardo Teixeira Brandão

Orientador

Departamento de Administração - PUC-Rio

Prof. Luis Felipe Jacques da Motta

Departamento de Administração - PUC-Rio

Prof. Leonardo Lima Gomes

Grupo Neoenergia

Prof. João Pontes Nogueira

Vice-Decano de Pós-Gradução do CCS

Rio de Janeiro, 18 de outubro de 2007 
Todos os direitos reservados. É proibida a reprodução total ou parcial do trabalho sem autorização da universidade, do autor e do orientador.

\section{André Luiz de Souza Portugal}

Graduou-se em Ciências Contábeis pela PUC-Minas Gerais e obteve pós-graduação em Gestão Empresarial na PUC-Rio de Janeiro. Trabalhou na PricewaterhouseCoopers, Telemar e no BNDES. Atualmente trabalha na BHP Billiton.

Ficha Catalográfica

Portugal, André Luiz de Souza

Aplicação da teoria das opções reais na avaliação de uma usina hidrelétrica / André Luiz de Souza Portugal ; orientador: Luiz Eduardo Teixeira Brandão. - 2007.

135 f. : il. ; $30 \mathrm{~cm}$

Dissertação (Mestrado em Administração)-Pontifícia Universidade Católica do Rio de Janeiro, Rio de Janeiro, 2007.

Inclui bibliografia

1. Administração - Teses. 2. Avaliação de investimentos. 3. Opções reais. 4. Incertezas. 5. Flexibilidade gerencial. 6. Geração de energia. I. Brandão, Luiz Eduardo Teixeira. II. Pontifícia Universidade Católica do Rio de Janeiro. Departamento de Administração. III. Título. 


\section{Agradecimentos}

Em primeiro lugar, a Deus.

Ao meu Professor Orientador Luiz Brandão, pelas inestimáveis contribuições de conhecimento.

Aos meus pais, pela oportunidade de terem me concedido a vida e a condição de pensar.

À minha mulher Raquel, pela confiança, compreensão e renúncia, e a quem dedico essa dissertação.

À minha filha Lara, que veio ao mundo em meio a essa pesquisa. 


\section{Resumo}

Portugal, André Luiz de Souza.; Brandão, Luiz Eduardo Teixeira. Aplicação da teoria das Opções Reais na avaliação de uma usina hidrelétrica. Rio de Janeiro, 2007. 135 p. Dissertação de Mestrado - Departamento de Administração, Pontifícia Universidade Católica do Rio de Janeiro.

O significativo potencial hídrico do Brasil tem gerado interesse para investimentos no setor de geração de energia hidrelétrica. No entanto, os métodos de avaliação financeira tradicionalmente utilizados como o Fluxo de Caixa Descontado (FCD) não incorporam as opções que os investidores possuem para gerenciar suas decisões de investimento de capital, e, em consequência, o valor do ativo é por vezes subavaliado. Nessa dissertação, avaliamos, por meio da utilização da Metodologia das Opções Reais, a viabilidade financeira de um projeto de uma usina hidrelétrica cuja capacidade de geração pode ser expandida ao longo do prazo da concessão. Para tanto, foram consideradas as incertezas relacionadas ao preço da energia, à vazão de águas na região do projeto, ao fator de perda na geração, aos indicadores macroeconômicos TJLP e IGP-M, além da possibilidade do investimento ser adiado para uma data futura. Assumindo que o preço spot de energia segue um processo de reversão à sua média histórica de longo prazo, o valor das flexibilidades analisadas não é significativo. No entanto, a análise de sensibilidade envolvendo as variáveis "volatilidade" e "investimento para expansão" revelou que o valor do projeto aumenta de $\mathrm{R} \$ 1,449$ milhões para aproximadamente $\mathrm{R} \$ 1,650$ milhões. Dado o alto grau de incerteza associado à oferta futura de energia elétrica no Brasil, concluímos que a Metodologia das Opções Reais oferece uma melhor estimativa do real valor de um projeto de investimento flexível, devido à existência desta incerteza nos parâmetros utilizados no modelo.

\section{Palavras-chave}

Avaliação de Investimentos; Opções Reais; Incertezas; Flexibilidade Gerencial; Geração de Energia. 


\section{Abstract}

Portugal, André Luiz de Souza.; Brandão, Luiz Eduardo Teixeira. An Application of Real Options Theory to the valuation of a hydroelectric power plant. Rio de Janeiro, 2007. 135 p. Dissertação de Mestrado Departamento de Administração, Pontifícia Universidade Católica do Rio de Janeiro.

The significant hydric potential available in Brazil has been attracting investments in this business area. On the other hand, traditional valuation methods such as Discount Cash Flow (DCF) do not incorporate the value of the options investors possess when managing their capital investment decisions and as a result, the value of these assets may be undervaluated. In this dissertation, we use the Real Options Approach to analyze the financial feasibility of a hydroelectric power plant project that can expand its generation capacity throughout its concession life. We consider uncertainties such as the spot price of energy, the water flow in the construction region of the project, the energy generation loss factor, macroeconomic parameters such as the TJLP interest rate and the IGP-M inflation rate, and also the possibility that the capital investment decision be postponed. Considering that the spot price of energy follows a long-term mean reversion process, the value of the flexibilities analyzed is not significant. Nevertheless, a sensitivity analysis of the "volatility" and "investment required for an expansion" parameters shows that the value of this project increases from $\mathrm{R} \$ 1.449$ millions to approximately $\mathrm{R} \$ 1.650$ millions. Given the high level of uncertainty regarding the future supply of energy in Brazil, we concluded that the Real Options Approach offers a better valuation of a flexible investment project given the uncertainty concerning the parameters used in the model.

\section{KeyWords}

Investment Valuation; Real Options; Uncertainties; Managerial Flexibility; Energy Generation. 


\section{Sumário}

1. Introdução 13

1.1. Objetivos do estudo 15

1.2. Delimitações do estudo 15

1.3. Relevância do estudo 16

1.4. Definição dos termos $\quad 17$

2. Referencial teórico 19

2.1. O processo de análise de projetos de investimento 19

2.2. O método do FCD 21

2.2.1. As variáveis que compõem o método 23

2.2.1.1. Fluxos de caixa futuros 23

2.2.1.2. Taxa de crescimento dos fluxos de caixa 24

2.2.1.3. Taxa de desconto dos fluxos de caixa 26

2.2.2. Críticas à aplicação do método 29

2.3. Breve abordagem do mercado de opções financeiras 30

2.4. A teoria das Opções Reais 32

2.4.1. Conceitos fundamentais $\quad 35$

2.4.1.1. A abordagem da certeza equivalente 36

2.4.1.2. A abordagem do portfólio replicado 37

2.4.1.3. A abordagem probabilística neutra ao risco 40

2.4.1.4. A hipótese do "Marketed Asset Disclaimer" 42

2.4.1.5. Os processos estocásticos $\quad 44$

2.4.1.5.1. Propriedade de Markov 44

2.4.1.5.2. Processo de Wiener 45

2.4.1.5.3. Lema de Itô 48

2.4.1.5.4. O modelo de reversão à média ("MRM") 52

2.4.1.6. O tratamento dos riscos associados às Opções Reais 53

2.4.2. O modelo de Black-Scholes 54

2.4.3. Taxonomia das opções reais 61 
2.4.4. Modelos de avaliação das Opções Reais 64

2.4.4.1. O modelo binomial $\quad 64$

2.4.4.2. A árvore de decisões 66

2.4.4.3. "Contingent Claims Analysis" 68

2.4.4.4. A utilização da Simulação de Monte Carlo ("SMC") 69

2.4.4.5. Programação dinâmica 72

2.4.4.6. Outros modelos 73

3. Metodologia 75

3.1. Tipo de pesquisa $\quad 75$

3.2. Coleta de dados $\quad 75$

3.3. Tratamento dos dados 76

3.4. Limitações do método 76

4. O estudo de caso 79

4.1. Introdução $\quad 79$

4.2. Estrutura burocrática do setor elétrico Brasileiro 87

4.3. O projeto da usina hidrelétrica 90

4.4. Definições das premissas 92

4.4.1. Premissas macroeconômicas $\quad 92$

4.4.2. Aspectos relacionados ao orçamento de capital 92

4.4.2.1. Investimentos 93

4.4.2.2. Depreciação e amortização 94

4.4.3. Receitas operacionais 95

4.4.3.1. Dados físicos 95

$\begin{array}{ll}\text { 4.4.3.2. Preços e reajustes } & 97\end{array}$

4.4.4. Impactos tributários 98

4.4.5. Custos operacionais 100

4.4.5.1. Transmissão e geração 101

4.4.5.2. Operação e manutenção 101

4.4.5.3. Concessão pública 101 
4.4.5.4. Outros custos operacionais 102

4.4.6. Fontes de recursos e estrutura de capital 104

4.4.6.1. Recursos de terceiros 105

4.4.6.2. A definição da taxa de desconto do projeto 106

4.5. Avaliação pelo método do FCD 107

4.6. Avaliação pela teoria das Opções Reais 113

4.6.1. Modelagem do ativo básico 115

4.6.2. As opções de expansão 117

4.6.3. Análise de sensibilidade 119

5. Conclusões 122

6. Referências bibliográficas 126 


\section{Lista de tabelas}

Tabela 1 - Os parâmetros das opçõs de compra e

de venda

Tabela 2 - Comparação entre opções financeiras e

reais

60

Tabela 3 - Potencial de geração elétrica no Brasil

Tabela 4 - Potencial hidrelétrico brasileiro por bacia

hidrográfica

Tabela 5 - Demanda de energia elétrica por setores da

economia

84

Tabela 6 - Resumo das premissas macroeconômicas

92

Tabela 7 - O orçamento de capital do projeto

93

Tabela 8 - Os custos pré-operacionais do projeto

93

Tabela 9 - Taxas anuais de depreciação

94

Tabela 10 - Dados operacionais por turbina de geração

95

Tabela 11 - Premissas tributárias da modelagem

financeira

99

Tabela 12 - Cronograma de investimentos de capital

do projeto sem expansão

104

Tabela 13 - Cronograma de liberações de capital de

terceiros

Tabela 14 - A modelagem utilizada para as variáveis

de incerteza

Tabela 15 - As volatilidades associadas ao projeto

Tabela 16 - Cronograma de distribuição de dividendos

do projeto

Tabela 17 - Matriz de sensibilidade do valor do projeto 


\section{Lista de figuras}

Figura 1 - Modelos de Avaliação Financeira $\quad 21$

Figura 2 - Relação entre a capacidade de reação dos

investidores e a probabilidade de se receber novas informações

Figura 3 - Analogia entre o modelo de Black-Scholes e

a teoria das Opções Reais

Figura 4 - Taxonomia das opções reais

Figura 5 - Equivalência entre os valores do ativo

replicado e de uma opção

Figura 6 - O processo de Simulação de Monte Carlo

Figura 7 - Produção mundial de energia hidrelétrica em 2004

Figura 8 - Mapa de bacias hidrográficas do Brasil 81

Figura 9 - Sistema Interligado Nacional $\quad 82$

Figura 10 - A operação de uma usina hidrelétrica $\quad 91$

Figura 11 - Comportamento histórico da vazão de águas

na região do projeto

Figura 12 - Série histórica de preços spot de energia

praticados na CCEE

Figura 13 - O modelo de fluxo de caixa

Figura 14 - O valor esperado do projeto calculado a partir do @Risk

Figura 15 - Análise de regressão da modelagem financeira

Figura 16 - A modelagem do ativo básico

Figura 17 - O valor esperado do projeto calculado a partir do DPL

Figura 18 - A modelagem das opções de expansão

Figura 19 - O valor esperado do projeto expandido

Figura 20 - Análise de sensibilidade da volatilidade do projeto

Figura 21 - Análise de sensibilidade do investimento para

expansão 


\section{Anexos}

Anexo I - Modelagem dos fluxos de caixa descontados 130

Anexo II - Premissas utilizadas nas projeções dos fluxos

de caixa

133

Anexo III - Sumário das operações por turbina 